\title{
Teoria da adjunção: predicação e relações "temáticas"
}

\author{
Carlos Franchi \\ Unicamp/USP
}

\section{Advertência necessária}

Nesta versão limito-me aqui a aspectos introdutórios e principais justificações empíricas (deixando de reproduzir os itens sobre adjetivos, advérbios, preposições e gerúndio). Para facilitar a comunicação, evito entrar desde logo na tecnicália da lógica combinatória e da gramática categorial ${ }^{1}$ em que desenvolvo minha pesquisa. Isto oculta muitos aspectos do modelo teórico, mas facilita nosso diálogo.

\section{INTRODUÇÃO}

T embre-se que Predicação se concebe, nestes textos, como uma relação de sentido entre expressões lingüísticas, ou seja, determinada pelas propriedades semânticas dos itens lexicais e das combinações de itens lexicais constituintes de uma unidade sintática. Lembre-se, ainda, que a Predicação não se restringe a uma 
relação semântica entre itens lexicais, mas envolve expressões complexas em processos componenciais e composicionais. Este texto visa somente a mostrar as conseqüências dessas assumpções em um domínio descritivo restrito da gramática do português: as estruturas de adjunção. Elas se incluem entre as instâncias de Predicação, sendo o adjunto o Predicado e atribuidor do papel temático a seu argumento.

$\mathrm{Na}$ teoria gerativa, a adjunção é uma estrutura bem definida tanto para quem adota a notação X-barra, como para quem adota a notação proposta no programa minimalista. CHOMSKY (1992), nos esquemas X-barra, admite as estruturas de adjunção de projeções máximas às cateforias X" e de núcleos à categoria X. Formalmente, a adjunção se distingue da "estrutura argumental" por conter uma projeção que reitera o tipo categorial do constituinte a que um outro se adjunge ou, com conseqüências sintáticas deriváveis, ${ }^{2}$ por construirse uma categoria composta de dois segmentos do mesmo tipo categorial, idéia que prevalece na notação minimalista (b):

(1) Estruturas de adjunção

a -

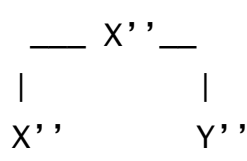

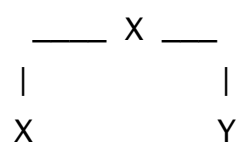

b-

(2) Estrutura argumental (de complementação):
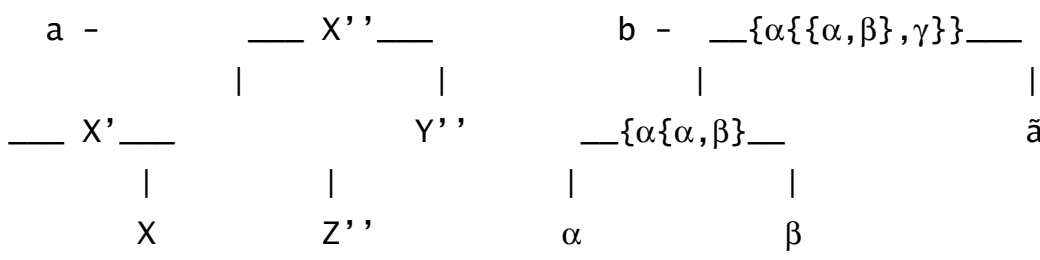
Vou assumir que as estruturas de adjunção formalmente definidas são a representação mais adequada das relações de Predicação a que a gramática tradicional se refere, em termos funcionais, como "adjuntos adnominais" (ou atributos) e "adjuntos adverbiais", entre os quais se incluem sintagmas preposicionados. ${ }^{3}$ Começo por apresentar e discutir algumas propriedades sintáticas e semânticas que se representam nessas estruturas.

1.

As representações em (1) expressam uma das propriedades fundamentais da estrutura de adjunção: as adjunções são um tipo de operação que "preserva a estrutura", ou seja, mantém-se o mesmo tipo categorial do operando no resultado da operação. Em nossos termos: os adjuntos são Predicados que tomam como argumento uma expressão de uma categoria á e constroem com ele uma expressão da categoria $\alpha .{ }^{4}$ Assim, informalmente, um adjetivoadjunto toma um nome como argumento e constrói um novo nome. Um advérbio toma um verbo (ou uma sentença) como argumento e contrói um novo verbo (ou nova sentença).

Do ponto de vista da interpretação, a adjunção se contrapõe à "estrutura argumental", em que os predicadores atribuem na relação de irmandade os seus papéis temáticos, como uma estrutura não-temática, no sentido de que o adjunto não estabeleceria uma relação temática com o constituinte a que se adjunge ou, pelo menos, não recebe dele um papel temático. Se minha análise em 0.2 está correta, convém expressar esta propriedade semântica em outros termos. De fato, tratamos também a adjunção como uma estrutura semântica de Predicação, especificamente entre o adjunto-predicador e o argumento a que se adjunge. Termos funcionais como predicado e argumento são relativos, ${ }^{5}$ pelo que, para evitar confusão, passo a contrastar as duas estruturas pelos termos - "estrutura de complementação" e "estrutura de adjunção". Mais: dado que tratamos as chamadas relações temáticas, derivativamente, como expressando 
o conteúdo semântico da Predicação, a relação entre o adjunto e seu argumento é também uma relação temática.

O modo mais simples de expressar essa propriedade é derivála definicionalmente dessa "rede" de relações. Os Predicados "modificadores" da gramática tradicional, a que estamos fazendo corresponder ainda sem discussão a estrutura sintática de adjunção, saturam saturam o papel temático hierarquicamente proeminente ${ }^{7}$ sobre argumento já tematizado (ROTHSTEIN, 1983; ZUBIZARRETA, 1982) ou já "theta-relacionado" (EMONDS, 1985). Mais precisamente:

(3) a) Núcleos X e Y são relacionados-theta se e somente se a projeção máxima de um deles possui um papel temático em relação ao outro (Emonds);

b) Duas projeções máximas são m-relacionadas-theta se e somente se seus núcleos são relacionados-theta;

c) Adjuntos saturam o papel temático nuclear proeminente em um argumento já m-relacionado-theta.

Como se observa, nessa álgebra de relações, a relação-theta e a mrelação-theta são simétricas. Mas como o faz Emonds, defino essas relações como anti-transitivas.

Ora, caracterizar o adjunto como tomando um argumento já mrelacionado-theta a um outro predicador, implica que um dos papéis temáticos de sua representação lexical seja saturado externamente, e não na posição de especificador. ${ }^{8}$ Para orações como (16-a,b, c), essas relações se exemplificam em (17-a,b,c):

(4) a - João rasgou o livro relativo a esse problema,

b - João leu um livro sobre Chomsky,

c - João falou contrariamente ao esperado,

d - João dormiu sobre o tapete; 


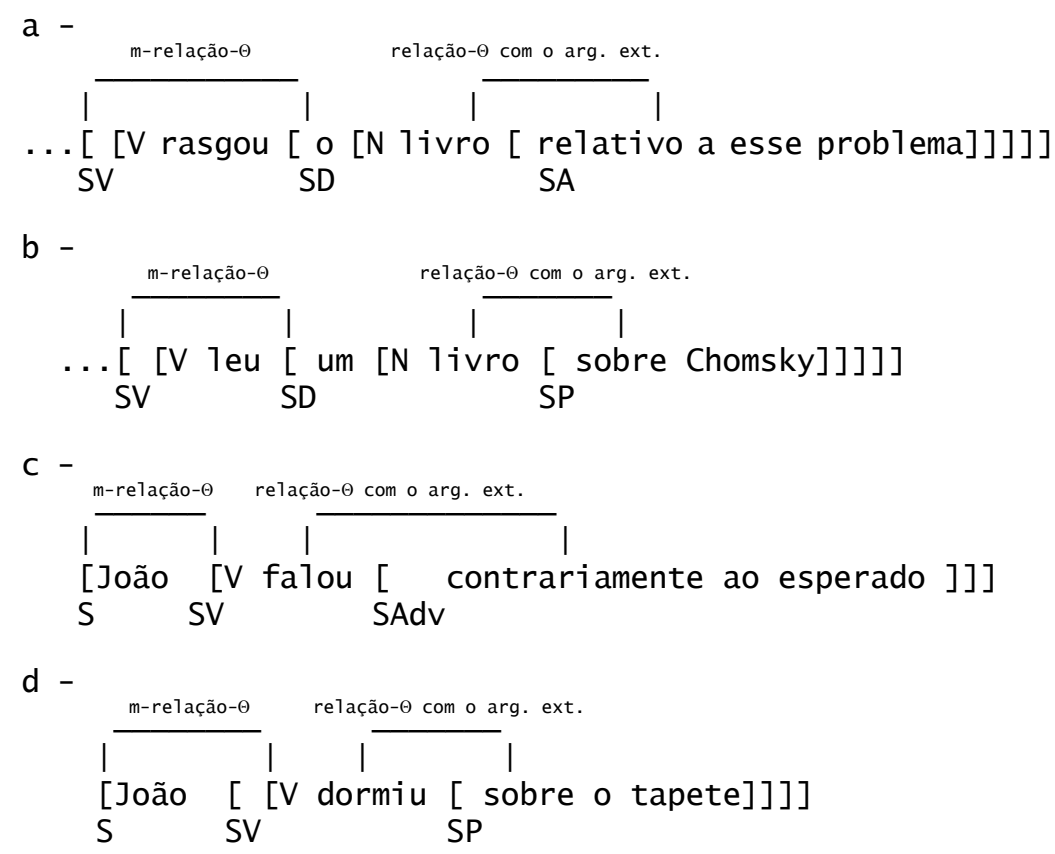

Duas observações são indispensáveis. Lembre-se que a forma abstrata por que caracterizamos a Predicação e as relações temáticas, incluem como predicadores e atribuidores de papéis temáticos adjetivos, advérbios e preposições. Entendam-se, ainda, as representações informais de (17) como ilustrando dois processos distintos, correspondentes, cada um deles, à estruturação sintática e à estruturação semântica: de um lado, a construção de uma estrutura sintagmática no sentido tradicional; de outro a construção da estrutura de sentido correlata.

Neste ponto, podemos tornar mais precisa a maneira pela qual concebemos a realização do princípio de transparência que, em 0.1, se dizia exigir que as operações construtivas do sistema sintático correspondessem a relações específicas no sistema semântico a que se associam por direta de interpretação. ${ }^{9} \mathrm{Na}$ projeção $\{\alpha\{\Phi\}\}$ (ou X") de uma estrutura de complementação as relações temáticas se interpretam, a cada passo, como orientadas do núcleo a (ou X) aos 
argumentos; ao contrário, na projeção $\{\alpha, \alpha\{\Phi\}\}$ (ou [XX]) da adjunção, as relações temáticas se orientam do adjunto para o núcleo.

Entre parêntesis, observe-se que se aumenta excessivamente o poder descritivo da gramática se se deixa aberta a interpretação teórica do formalismo por mais restritiva que seja a sintaxe em que se constrói. Por exemplo, postular que o princípio meta-lingüístico da sucessão (STOWELL, 1981) na notação X-barra seja interpretado livremente pela natureza "elsewhere" da categoria em posição de especificador, podendo engrendar-se como núcleo qualquer categoria. Assim, o que se propõe no parágrafo anterior estabelece condições de possibilidade das estruturas sintáticas de complementação e de adjunção como uma hipótese fortemente restritiva. ${ }^{10}$ Além disso, com a formulação proposta, a relação intuitiva de "modificação" se subsume na orientação da relação temática. ${ }^{11}$

Um outro corolário de (15-c): os adjuntos podem tematizar tanto argumentos de um outro predicado (predicação de 1a. ordem), quanto predicadores (predicação de $2 \mathrm{a}$. ordem ), pois categorias em ambas as funções podem estar simetricamente m-relacionadas-theta. Isto somente distingue (inclusive morfologicamente) os adjuntos adnominais em (17-a,b) dos adjuntos adverbiais em (17-c,d).

\section{1.}

Para se compreender melhor natureza funcional do adjunto, vale, aqui, perguntar-nos em que contextos categorias como de adjetivos e preposições se realizam em suas projeções máximas, como complexos funcionais completos (CHOMSKY, 1986), realizando, portanto, todas as relações temáticas internamente. Suscintamente, alguns exemplos, que retomo do texto sobre a Predicação, serão suficientes. Considerem:

(6) a) João é inteligente,

d) A sessão é na sala 10,

c) João acha o aluno inteligente,

d) João prefere este móvel no corredor. 
Seguindo de perto STOWELL (1983) e CHOMSKY (1986, 1995-b) as orações de (18) exemplificam as chamadas construções reduzidas - "small-clauses" - cuja descrição estrutural (sempre informalmente) seria:

$$
\begin{aligned}
& \text { [ é [ João inteligente ]] } \\
& \text { [ a sessão ] [ na sala } 10 \text { ] } \\
& \text { I } \quad \mathrm{A} / \mathrm{P} \\
& \text { [ João acha o aluno inteligente ] } \\
& \text { S SV A/P }
\end{aligned}
$$

Exemplos mais interessantes, por serem pouco considerados na teoria, são:

(8) a) [Outra sopa igual à de ontem] parece mesquinharia sua,

b) * A sopa (que é igual à de ontem) é mesquinharia;

(9) b) Não admito [o pé sobre a mesa],

b) * Não admito o pé (que está sobre a mesa);

E' fácil observar que a predicação é uma mesquinharia e de não admito não incide sobre núcleos nominais (sopa, pé), mas sobre todo complexo relacional construído pelo adjetivo igual e pela preposição sobre. O que é uma mesquinaria é que a sopa seja igual à de ontem e o que não admito é que se ponha o pé sobre a mesa. Assim, a representação categorial de (20-a) e (21-a), no aspecto em discussão, é a mesma proposta para as orações reduzidas adjetivais e preposicionais em (19).

Exemplos similares se encontram no interior de sintagmas descritivos com a preposição com (na maioria dos contextos, ambíguas entre uma leitura do sintagma adjetival ou preposicionado como adjunto, ou formando um complexo funcional complexo): 
(10) a) Com [esses doutores cheios de empáfia] prefiro ir embora,

b) *Prefiro ir embora com esses doutores;

(11) a) Com [o FHC na presidência], eu desisto da política,

b) *Com o FHC eu desisto da política.

A representação como um complexo funcional adjetivo ou preposicional dessas construções, fazendo a predicação incidir sobre a relação estabelecida sobre a proposição que expressa e não sobre os sintagmas nominais especificadores, explica a aparente ausência de concordância em orações como:

(12) a) Batatas cruas não é bom para o estãmago;

b) Uma casa igual a essa é que seria bom;

c) Baratas na manteiga é muito bom;

d) Os pés encima da mesa é uma indelicadeza.

Mantém-se, de (8) a (11), a interpretação argumental estrita das posições sintáticas de complemento e especificador - uma estrutura de complementação, que se contrapõe-se nítidamente à estrutura de adjunção. Naquelas, como aliás na tradicional estrutura de predicação, o especificador está em uma relação de "nexo" (JESPERSEN, 1924) com o Predicado nucleado por um adjetivo ou uma preposição: é um Sujeito, no sentido de STOWELL (1983).

Stowell também estende a noção de predicação sintática a todas as categorias substantivas maiores - S, SN, SV, SA, SP: todas podem conter uma posição estrutural de Sujeito. Isso lhe permite generalizar e definir uma posição estrutural de Sujeito (para distinguir da função de sujeito da oração):

(13) O sujeito de um sintagma X" é o argumento diretamente dominado por X" (ou seja, o seu especificador).

A definição dá conta diretamente da noção de sujeito gramatical da oração que se realiza (via move- $\alpha$ ou não) na posição de especificador de I, fazendo I' corresponder ao predicado tradicional que 
inclui o sintagma-verbal como seu complemento. Dá conta, ainda, da noção de "sujeito" de um SN, relevante, por exemplo, para questões como as de atribuição de caso (CHOMSKY, 1981), controle (CHOMSKY, 1986, p. 122-123) e vinculação (CHOMSKY, 1981). ${ }^{12}$ Além disso, no caso das "small-clauses", que envolvem necessariamente uma relação de Predicação, pode-se dispensar a incômoda etiqueta "SC" que não possui motivação categorial satisfatória, sem perda do valor explicativo dessa estrutura em relação a outros fenãmenos sintáticos (CHOMSKY, 1986-b).

Mas agora se coloca mais evidente a relevância teórica das estruturas de adjunção. Comparem-se as orações de (20) a (23) com:

(14) $\left[_{\mathrm{N}}\right.$ Outra sopa [ igual à de ontem]] está na mesa,

(15) Estou vendo $\left[_{\mathrm{N}}\right.$ o pé $\left[_{\mathrm{P}}\right.$ sobre a mesa]];

(16) Eu vivo com $\left[_{\mathrm{N}}\right.$ esses doutores $\left[_{\mathrm{A}}\right.$ cheios de empáfia]],

(17) Nem todos concordam com $\left[_{N}\right.$ esse cara $\left[_{P}\right.$ na presidência]].

A estrutura de ajunção já não é opaca: a Predicação sobre o sintagma complexo incide sobre o núcleo nominal ${ }^{13}$ o que explica os acarretamentos (respectivamente):

(18) A sopa está na mesa,

(19) Estou vendo o pé,

(20) Eu vivo com alguns doutores,

(21) Nem todos concordam com o cara.

\section{2.}

Posso voltar, agora, às estruturas de adjunção. Deve haver vários mecanismos de saturação de um papel papel temático se se admite a atribuição de um segundo papel temático a um argumento 
já m-theta-relacionado, via "predicação secundária"14 e adjunção. Note-se, porém, que a atribuição de um papel temático é uma relação de Predicação orientada, assimétrica e, em certos casos, transitiva, ao contrário da (m-)theta-relação definida em (15). Podem-se distinguir três situações, duas das quais discutirei neste e no próximo item.

Na versão chomskyana do gerativismo, a atribuição de papéis temáticos é estritamente local: ela se dá direta (e, para alguns autores componencialmente ${ }^{15}$ ) em relação de "irmandade" nas estruturas sintagmáticas. Entretanto, a sintaxe não tem nada a dizer sobre "atribuição de papel temático", ou melhor, sobre a relação semântica entre predicadores e seus argumentos, quando se assume a estrita autonomia dos planos semântico e sintático (CULICOVER, 1988). Cabe à sintaxe explicitar essa relação: torná-la visível. Como observa BAKER (1988), a teoria dos Casos e o princípio de visibilidade é uma gramaticalização formal relacionada à necessidade "a priori" de se ser capaz de deduzir relações semânticas da estrutura superficial. ${ }^{16}$

As representações dos itens lexicais incluem, como parte da competência do falante/interprete o esquema relacional semântico da diátese dos predicadores e, pois, admitidas as hipóteses que venho desenvolvendo, a interpretação dessa relação é exclusivamente parte do processo interpretativo. ${ }^{17} \mathrm{Na}$ maioria dos casos das adjunções, entretanto, a relação de irmandade se interpreta como saturação do papel temático no argumento modificado. Assim em:

(22) a - João [ fala alto ],

b - João [escreve a lápis];

(23) a - A [ passagem [ relativa ao gerativismo ] ] ...,

$\mathrm{b}$ - O [ vaso [ encima da mesa ] ] ...;

(24) a - O [ vaso [ que está encima da mesa ] ] ...,

b - Esses são [papéis para rabiscar];

(25) Acho [esse garoto inteligente], 
Nesses exemplos, trata-se, sempre, de casos de "predicação direta" ou "primária". Exemplos, porém, como (26)-(29):

(26) a - João entrou no quarto angustiado,

b - João entrou no quarto com calafrios,

(27) a - (O leite está frio e) o bebê bebe o leite quente,

b - (O leite está sem açucar e) o bebê bebe o leite com açucar.

(28) A argumentação funciona contrariamente ao esperado,

(29) João pagou caro essa consulta,

mostram-nos que a interpretação das relações temáticas, em casos de adjunção, nem sempre é estritamente local no sentido acima: o adjunto pode determinar tematicamente um argumento do predicador a que se adjunge e pela mediação desse predicador. De fato, angustiado/com calafrios e contrariamente atribuem composicionalmente um papel temático ao sujeito, respectivamente, João e argumentação; quente/com calafrios e caro, ao complemento, respectivamente leite e essa consulta. ${ }^{18}$ Observe-se que (26)-(29) acarretam semanticamente:

(30) a - Foi angustiado que João entrou no quarto,

b - João tinha calafrios, quando João entrou no quarto;

(31) O bebê bebe o leite quando/se ele está quente/com açúcar,

(32) A argumentação foi contrária ao esperado.

(33) Essa consulta foi cara. ${ }^{19}$

É a relação temático-predicativa que está sujeita a restrições seletivas, na medida em que se entende como uma família de acarretamentos e pressuposições lexicais partilhadas por um determinado argumento de um predicador. Ora, pode-se notar que, nos casos de uma atribuição composicional do papel temático, não é 
entre o verbo e seu adjunto que se dá a seleção categorial, mas entre um argumento do verbo e seu adjunto:

(34) a - João entrou no quarto angustiado,

b - O armário entrou no quarto desmontado,

c - * João entrou no quarto desmontado, [no sentido relevante]

d - *O armário entrou no quarto angustiado;

e é essa mesma condição de compatibilidade semântica (de "predicabilidade") que favorece a interpretação da orientação da relação para o sujeito ou para o complemento:

(35) a - O bebê, agora, está bebendo o leite quente/com açúcar,

b - ? O bebê bebe o leite, se/quando o bebê está quente,

c - O bebê bebe o leite, quando o leite está quente,

d - * O bebê bebe o leite, se/quando o bebê está com açúcar.

e - O bebê bebe o leite, se/quando o leite está com açúcar.

(36) a - João pagou rápido/caro essa consulta,

b - João foi rápido/*caro para pagar a consulta,

c - Essa consulta foi cara/*rápida [no sentido relevante].

Enfim, um outro argumento a favor da formulação em questão, está na anomalia semântica de:

(37) a) * A pedra rolou pelo barranco intencionalmente,

b) * O vaso quebrou intencionalmente,

c) * A porta abriu para fazer passar o piano.

A teoria de STOWELL (1983) dá conta satisfatoriamente desse fenômeno quando analisa os predicados secundários. Em orações como as de (26) e (27), o sintagma nominal-sujeito e o sintagma nominal objeto são tematicamente relacionados ao verbo principal. Por outro lado, a predicação expressa pelos predicadores angustiado/ com calafrios, em (26), e quente, em (27) se subordinam de algum modo "adverbialmente" ao verbo principal, como se vê em (31) e em: 
(38) João estava angustiado/com calafrios, quando entrou no quarto.

Para STOWELL (1982, p. 304 e sgs.), a estrutura dessas duas orações com predicado secundário inclui uma "small-clause"; não se trata, entretanto, de uma "small-clause" complemento, como no caso de (6)/(7), mas de uma oração em adjunção ao sintagma verbal: ${ }^{20}$

(39) a - João $\mathrm{O}_{\mathrm{i}}\left[\mathrm{L}_{\mathrm{V}}\right.$ entrou no quarto] $\left[_{\mathrm{A}} \mathrm{PRO}_{\mathrm{i}}\right.$ angustiado] $]$, $\mathrm{V}$

b - O bebê [ [ $\mathrm{V}_{\mathrm{V}}$ bebe o leite] $\mathrm{I}_{\mathrm{A}} \mathrm{PRO}_{\mathrm{i}}$ quente]]. $\mathrm{V}$

Nessa proposta, a relação de dependência (aspectual) da interpretação do predicado secundário à predicação primária se expressa pela subordinação na estrutura de adjunção e, na estrutura de controle de PRO por João e por leite, recupera-se a estrita localidade da atribuição dos papéis temáticos e se dissolve a "dupla" atribuição de papel temático a João e leite - o da predicação primária e o da predicação secundária.

A proposta de Stowell, embora corresponda à análise intuitiva que faço dessas orações (e, pois, a reforce), não se ajusta inteiramente ao quadro teórico em que venho pesquisando. Em uma gramática categorial (que está sempre aqui atrás das cortinas), muitas vezes se assume que a interpretação semântica se faz a partir de uma "estrutura superficial". ${ }^{21}$ Nesse caso, não faz sentido falar-se de categorias vazias. Além disso, não há como tratar, no mesmo esquema, o fenãmeno semelhante que ocorre com a adjunção adverbial, exemplificada em (38) e (39). Uma hipótese mais abrangente seria preferível como a de tratá-lo via atribuição composicional, transitiva que permite, em ambos os casos - da "predicação secundária" e da construção adverbial, derivar a "dupla atribuição" de papéis temáticos interpretação diretamente das relações de Predicação na sentença. 
Definamos informalmente uma composição de relações: $:^{22}$

(40) Suponhamos duas relações $\alpha: X$--> Y e $\beta: Y \longrightarrow$ Z . A composição $\beta * \alpha$ dessas relações se obtém aplicando-as uma após a outra $(\alpha-\beta)$ desde que isso faça sentido, ou seja, desde que o domínio de $\beta$ seja o codomínio de $\alpha$. Mais formalmente: $(\beta * \alpha)(r)=\beta(\alpha(r))$,

que se pode representar no grafo de dependências:

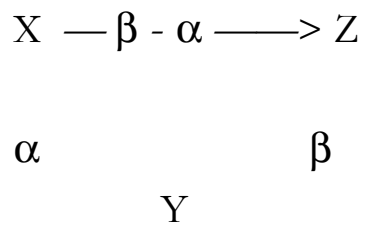

Nessa definição, "fazer sentido" se interpreta lingüisticamente em termos de compatibilidade semântica ou seleção lexical. A composição não se instancia para todos os X, Y, Z, a não ser que Z seja compatível semânticamente com X. Assim, em alguns casos, o Predicado expresso por um adjunto do sintagma verbal toma como argumento exclusivamente o núcleo verbal:

(42) a - João advertiu muito alto o colega,

b - * João estava muito alto quando advertiu o colega,

c - * João advertiu o colega quando muito alto.

ou exclusivamente um dos argumentos de que o sintagma verbal Predica:

(43) a - João foi encontrar triste/*tristemente o amigo,

b - João estava triste quando foi encontrar o amigo,

c - * O encontro de João com o amigo foi triste;

(44) João tem mais claros/*mais claramente os olhos, 
Outras vezes, embora compatível com o sintagma verbal, é também compatível com um dos argumentos permitindo uma sutil "dupla interpretação" que se manifesta numa escolha marcada morfologicamente:

(45) a - João saiu rápido/rapidamente da cena,

b - João foi rápido ao sair da cena,

c - A saída da cena foi rápida;

(46) João comprou caro/caros os livros

Essa diferença de escopo do adjunto (adverbial ou não) nos parece ser o fator decisivo na questão relativa à posição dos adjuntos. No caso dos adjuntos que se orientam para o sujeito, é conhecida uma certa liberdade de posições:

(47) a) Rapidamente/rapido João comprou o seu carro novo,

b) João rapidamente/rápido comprou o seu carro novo,

c) João comprou rapidamente/rápido o seu carro novo,

d) João comprou o seu carro novo rapidamente/rápido;

Ao contrário, se o adjunto é orientado exclusivamente para o objeto direto, ele não pode deslocar-se de dentro do sintagma verbal:

(48) a) * O garoto muito caro comprou os livros,

b) * O garoto estridentemente tirou notas do pistão,

c) * João completamente abriu a porta.

Dada a limitação imposta pela destinação do texto a um seminário, não vou estender-me aqui sobre isto. Tendo, entretanto, a recusar uma proposta como a de POLLOCK (1989)/CHOMSKY (1989) e preferir a linha aberta por Iatridou (1990), trazendo-lhe o reforço de uma argumentação baseada no fato acima apenas apontado.

O processo composicional pouco estudado que descrevemos para os adjuntos adverbiais e predicados secundários, também ocorre com adjuntos adnominais. Observem-se os exemplos: 
(49) a) O garoto de fisionomia pacata foi o escolhido,

b) O garoto pacato de fisionomia foi o escolhido;

(50) a) Os jardins verdejantes de uma grama fina se estendiam...

b) Os jardins de uma grama fina verdejante se estendiam...

Espero, porém, ter deixado claro que o processo composicional descrito neste item é exclusivamente interpretativo, dependendo somente do estabelecimento de uma correlação estreita entre a forma resultante das operações sintáticas e a estrutura do sentido.

\section{3}

Apresentei, em resumo, algumas propriedades sintáticas e semânticas da estrutura de adjunção, dando-lhe uma extensão bem mais ampla do que em geral admitem versões atuais da gramática gerativa, apesar de CHOMSKY (1995-b). À guisa de conclusão, gostaria de comentar brevemente o aspecto teórico-metodológico relativo à forma em que formulo o princípio de transparência que determina relações de interdependência entre a estrutura sintática e a estrutura semântica a cada passo da derivação. É necessário colocá-la, mesmo que em termos muito vagos, em um plano abstrato, envolvendo operações e relações bem gerais. "Minimalistas" em um sentido bem preciso.

Se nos limitamos, como me limitei, às operações e relações entre categorias substantivas, as operações sintáticas se limitam a selecionar itens lexicais, como objetos abstratos elementares, e a construir com eles objetos abstratos complexos. Aquilo em que me afasto da proposta de Chomsky é que o conjunto fechado de constantes lexicais sobre que a sintaxe opera é motivada, "de fora", pela proto-estrutura da eventualidade a ser descrita na proposição. Esta motiva a seleção lexical e determina a projeção dessa protoestrutura em várias estruturas sintáticas virtuais, possíveis, conforme o ponto de vista que o falante/interprete instaura sobre a eventualidade ou deve recuperar na interpretação. 
Seja qual for a operação construtiva ("merge", "concatenação", "aplicação"), ela expressa diretamente um correlato semântico - uma Predicação no domínio descritivo-explicativo a que me limitei neste texto. Por outro lado, a configuração sintática resultante - uma estrutura de complementação ou uma estrutura de adjunção - expressa diretamente a orientação da Predicação. Com isso, como observei, nessa estreita correspondência entre a forma sintática e o efeito de sentido, estabeleço um forte restrição não somente sobre o conjunto das configurações sintáticas possíveis, mas ainda sobre os termos que são licenciados nessas configurações. Esquematicamente, como mera ilustração:

$\begin{array}{lll}\mathrm{X}, \mathrm{Y} \text { são compatíveis semanticamente/predicáveis } & \rightarrow & \mathrm{X} \\ \text { X Predica de Y e X',Z são predicáveis } & \mathrm{X}^{\prime}\end{array}$

X'(componencialmente) Predica de Z e X", W são predicáveis $\quad \longrightarrow>\quad$ X” $\quad$ W

Em outros termos, busco assegurar que ao formalismo se "interprete" de modo determinado e unívoco na linguagem-objeto, o que não somente limita as representações "bem formadas" mas ainda restringe o conjunto das "análises" adequadas nesse formalismo. ${ }^{23}$

Nesse sentido, torna-se mais claro o que se deve excluir da sintaxe e tratar como um processo interpretativo. Por exemplo, podese simplificar a sintaxe em um sentido bem preciso de "parcimônia ontológica", evitando-se a postulação de "categorias vazias", como mostrei adotando uma regra de interpretação (o processo composicional) no caso da atribuição não-localmente de papel temático pelos adjuntos. ${ }^{24}$ Ainda esquematicamente, para uma oração como João saiu triste. 


$\mathrm{X}$, Y são compatíveis semanticamente/predicáveis $\longrightarrow \longrightarrow>$ saiu
$\mathrm{X}$ Predica de $\mathrm{Y}$ e $\mathrm{X}^{\prime \prime}, \mathrm{Z}$ são predicáveis
$\mathrm{Z}$ (em adjunção) Predica de $\mathrm{X}$ "
$\mathrm{P}(\mathrm{Z}, \mathrm{X}), \mathrm{P}(\mathrm{X}, \mathrm{Y}) \longrightarrow \mathrm{P}(\mathrm{Z}, \mathrm{Y})$ se $\mathrm{Z}$ e $\mathrm{Y}$ são predicáveis.

Não pretendo, evidentemente, ter construído um sistema mais "econômico", no sentido de CHOMSKY (1995-b), porque a simplificação em um componente é compensada pela incorporação do outro. Do mesmo modo que não vale contra minha proposta a crítica de ser "menos econômico". A questão é outra. A escolha de um instrumento lógico, de um sistema ou outro de objetos abstratos e do formalismo da linguagem representativa não é nunca inocente, mesmo quando se possa estabelecer formalmente que se trata de "linguagens" com a mesma capacidade gerativa ("variantes notacionais", como se costuma dizer para desconsiderar modelos alternativos). De um modo geral, se formalizam diferentes concepções de linguagem, quando se trata de teorias lingüísticas. Mas este é um ponto sobre que não me posso estender aqui. 


\section{NOTAS}

${ }^{1}$ Ver apêndice B ou, diretamente, AJDUKIEWICZ, 1935; BAR HILLEL, 1953; LAMBECK, 1961; LYONS, ; SHAUMJAN, 1965; FRANCHI, 1975; 1988; STEEDMAN, 1996, e os textos em OEHRLE, BACH \& WHEELER, 1988.

${ }^{2}$ No caso das adjunções tem-se que considerar a estipulação relativa à relação de dominância. Assume-se (MAY, 1985; CHOMSKY, 1986-b) que não existem, na estrutura de adjunção, duas categorias $\mathrm{X}^{\mathrm{n}}$, mas sim duas manifestações de uma mesma categoria e que a categoria $\mathrm{Y}$ adjunta em (7-a) não é dominada por X" nem por X em (b), embora incluída em X" e em X. Mais explicitamente (RAPOSO, 1992):

(i) a) Um segmento $\mathrm{x}$ de uma categoria $\mathrm{X}$ s-domina $\mathrm{Y}$ sse existe uma seqüência conexa descendente de uma ou mais setas de $\mathrm{x}$ a $\mathrm{Y}$;

b) X domina $\mathrm{Y}$ sse todos os segmentos de X s-dominam $\mathrm{Y}$; c) X exclui $\mathrm{Y}$ se nenhum segmento de $\mathrm{X}$ s-domina $\mathrm{Y}$.

As conseqüências incidem sobre princípios e regras cujo domínio direta ou indiretamente se configuram com base na relação de dominância.

${ }^{3}$ Assim pensam, entre outros, CHIERCHIA (1984) e WILLIAMS (1995), embora em outros quadros teóricos. Outros distinguem "predicação" de "modificação, como ZUBIZARRETA (1982), MARANTZ (1984) e JO NAPOLI (1989).

${ }^{4}$ Na gramática tradicional, ver JESPERSEN, 1924. No gerativismo, MARANTZ, 1984; CHOMSKY, 1992; nas gramáticas categoriais, ADJUKIEVICS, 1935; CURRY \& FEIZ, 1958; BAR-HILLEL, 1953.

${ }^{5}$ Por exemplo, em uma oração como:

(i) - João [[rasgou o bilhete] rapidamente]

rasgar Predica de o bilhete (como seu argumento); rapidamente Predica de rasgar o bilhete (como seu argumento); rasgar o bilhete rapidamente Predica de João (como seu argumento); e rapidamente Predica de João (composicionalmente pela mediação do sintagma verbal que toma como argumento).

${ }^{6}$ No nível léxico, os argumentos possuem o mesmo estatuto lógico, distinguindose somente pela relação temática. Poderia tratá-los todos como "sujeitos", como diz REICHENBACH (1947), ou como "complementos", como sugere TESNIÈRE (1959) e se diz na tradição da teoria de valências. Daí o nome - estrutura de complementação.

${ }^{7}$ Pressuponho, ao falar em argumento proeminente, várias coisas sobre que não posso estender-me aqui: a) que a escolha dos itens lexicais, sobre que a sintaxe opera na construção das orações, é motivada (não aleatória), ao contrário do que assume CHOMSKY (1995-b) com a noção de numeração; b) embora princípios 
como as do Critério- $\Theta$ e do princípio de projeção não operem estritamente na sintaxe (são princípios semântico-interpretativos (CHOMSKY, 1995-b; BRODY, 1993)) uma pré-estrutura do evento motiva essa seleção; c) o princípio metodológico de transparência, tal como formulado em 0.1, acarreta a manutenção do princípio de projeção, como poderoso intrumento de restrição às inúmeras e inevitáveis estruturas pré-FL mal formadas a que leva a versão minimalista de Chomsky; d) um princípio de hierarquia temática relaciona a estrutura argumental semântica dos predicados e a estrutura de complementação sintática.

${ }^{8}$ Um corolário de (15), para quem adotasse uma notação X-barra seria que, nas estruturas de adjunção, a extensão argumental se limita, no máximo, a categorias intermediárias X'. Daqui em diante, simplificarei as representações ao mínimo necessário para a compreensão do tópico estudado. Tenha-se, porém, sempre em mente os esquemas sintagmáticos de (13) e (14).

${ }^{9}$ Nisto o modelo mais se aproxima de pressuposto das gramáticas de Montague. Como observa BACH (1989, p. 8) a tese de Chomsky é a de que as línguas naturais podem ser descritas como um sistema formal. Montague acrescenta a essa idéia que as línguas naturais podem ser descritas como sistemas formais interpretados. Estamos a meio caminho: as línguas naturais podem ser descritas como sistemas formais que associam estrutura sintática e estrutura semântica (do sentido) que se incluem, entre outros fatores (como fatores pragmático-discursivos) no processo de interpretação.

${ }^{10}$ Isso é mais grave, ainda, quando se admite a proliferação de categorias funcionais, cada uma com a posição de especificador disponível para o movimento das mais variadas categorias. O caráter restritivo da imediata associação das sub-estruturas sintagmáticas a um correlato semântico determinado se mostra facilmente. A proposta exclui desde logo inúmeras análises correntes na teoria gramatical; por exemplo, a instanciação do especificador do verbo por operadores aspectuais ou intensivos ou advérbios (POLLOCK, 1989) ou do especificador de Aspecto por um advérbio predicativo (BELLETTI, 1990); descrições estruturais de construções resultativas (HOEKSTRA, 1988; HOEKSTRA \& MULDER, 1990):

$\mathrm{i}$ - John hammered $\left[_{\mathrm{AP}}\right.$ the nail flat].

STOWELL (1995) faz uma revisão de sua teoria das "small-clauses" e insiste na caracterização semântica dessas estruturas como a de uma predicação lógica, criticando extensões excessivas dessa noção descritiva a outras estruturas não predicativas. No caso de (i) a "small-clause" não expressa a Predicação e atribuição do papel temático do predicado primário a seu complemento. 
11 Dispensamo-nos, assim, de formulações estipulativas e parciais, como a que define "modificação" de ZUBIZARRETA (1982) - (i), ou outras como as de ROTHSTEIN (1983) - (ii), e CULICOVER \& WILKINS (1984) - (iii):

(i) Em configurações : $\left[{ }_{\mathrm{A}} \ldots \mathrm{x} \ldots \mathrm{y} \ldots\right],\left[{ }^{\mathrm{A}} \ldots \mathrm{y} \ldots \mathrm{x} \ldots\right]$, para categorias quaisquer $\mathrm{A}, \mathrm{x}, \mathrm{y}$, onde

$\mathrm{a}-\mathrm{A}=$ projeção de $\mathrm{y}$;

b - A domina imediatamente x e y;

c - $\quad \mathrm{x}=$ Adjetivo, Advérbio - $>\mathrm{x}$ modifica $\mathrm{y}$. ( $\mathrm{O}$ que quer dizer que y está no escopo de $\mathrm{x}$ ).

(ii) Os papéis temáticos dos adjuntos se atribuem somente na FL: Um papel temático de adjunto deve combinar-se na FL com o papel temático de um argumento.

(iii) Todo não-argumento X" deve estar ligado a um argumento que mutuamente o c-comanda.

${ }^{12}$ Considerem as orações:

(i) a - Cesar's destruction of the city,

b - * The city's destruction of Cesar

c - The city's destruction (by the enemies)

(ii) A destruição da cidade somente para $\mathrm{PRO}_{\mathrm{i}}$ satisfazer a própria raiva;

(iii) a - João $\mathrm{i}_{\mathrm{i}}$ detesta a imagem de $[\text { si mesmo }]_{\mathrm{i}}$ que ele tem,

b - João $O_{i}$ detesta a imagem de Pedro ${ }_{j}$ de si mesmo ${ }_{\left[*^{*} / j\right]}$,

Em (1-b) se observa a restrição à atribuição de caso genitivo ao complementopaciente do núcleo nominal, a não ser que em uma construção passiva (i-c). Em (ii), se pressupõe um agente implícito indispensável para a identificação referencial, via controle, do PRO-sujeito de satisfazer a própria raiva. Em (iii-b) a presença de um Sujeito acessível no sintagma nominal a imagem de si mesmo torna esse sintagma o domínio de vinculação da anáfora, ao contrário de (iii-c).

13 Tendo considerado elementos dêiticos e quantificacionais como operadores, opto pela estrutura do sintagma nominal como projeção do nome.

${ }^{14}$ Estou assumindo, sem discutir aqui, que o predicado secundário se representa em uma estrutura de adjunção. Ver ROTHSTEIN (1983) e STOWELL (1983, 1995). 15 Ver nota 9. 
${ }^{16}$ Esse sistema pode ser generalizado além do domínio dos casos morfológicos pois outros sistemas são certamente possíveis em inúmeras línguas: o princípio de visibilidade pressupõe somente uma "aberta" (overt) manifestação (explicitação formal) das relações semânticas.

${ }^{17}$ Lembre-se que estou assumindo uma gramática com um princípio de projeção que motiva e determina a seleção dos itens lexicais. A questão aqui não é por que adotar essa hipótese, mas por que não adotá-la: ou seja, se há informações semânticas associadas à representação dos itens lexicais, decidir se a sintaxe é inteiramente cega a essas propriedades não é uma questão de "economia" mas uma questão primeiramente empírica e em seguida metodológica.

${ }^{18}$ JACKENDOFF (1972) fala de advérbios "orientados para o sujeito" e advérbios "orientados para o objeto".

${ }^{19}$ Interessante notar que a preocupação mais forte de DAVIDSON (1967) quando formula sua teoria das locuções advérbiais é a de dar conta dos acarretamentos das sentenças com essas construções. Entretanto, a sua formulação elegante em uma lógica de primeira ordem não permite obter os acarretamentos mostrados em (42)-(45) a que nem se refere.

${ }^{20}$ A "small-clause" complemento não pode construir-se com PRO, visto que o "sujeito" é regido e recebe caso excepcionalmente do verbo principal. As "smallclause" com PRO em (47), em adjunção ao sintagma-verbal, são gramaticais: na teoria, a estrutura de adjunção constitui uma barreira à regência de seus constituintes por um predicador externo.

${ }^{21}$ É o que faço no final da introdução. Ver, por exemplo, STEEDMAN (1996). Em uma tradição gerativista, ver WILLIAMS (1995).

${ }^{22} \mathrm{Na}$ lógica combinatória essa composição de funções se define pelo combinador B de Curry e Feiz.

${ }^{23}$ Não é sem razão que tenho proposto que a "checagem" dos traços morfossintáticos que tornam "visíveis" essas relações semânticas para a interpretação se realize já na instanciação das operações construtivas dos sintagmas, ou seja, como parte das operações de "merge" ou similares.

${ }^{24}$ Uma análise que dispensa PRO nas infinitivas e gerundivas pode-se ver em CHIERCHIA (1984). WILLIAMS (1995) também desenvolve um sistema baseado na co-indexação dos índices- $\theta$ dos predicados e seus argumentos, que dispensa o recurso a variáveis para expressar vinculações. 